\title{
The Effect of Competitive Intelligence in Product \& Service Innovation Using A Need Pull Modell
}

\author{
Phathutshedzo Nemutanzhela \\ Faculty of ICT Tshwane University of Technology (TUT) \\ Pretoria, South Africa, Phathuts@gmail.com
}

\begin{abstract}
This paper discusses the findings of the study that was aimed at establishing the effect of Competitive Intelligence, hereafter referred to as $\mathrm{CI}$, on product and service innovations. A literature study revealed that $\mathrm{CI}$ and innovation are widely studied subjects, but the impact of CI on innovation was not well documented. CI has been widely acclaimed as a panacea to a lot of organizational problems. The study aimed at the innovative aspect. A descriptive study using both qualitative and quantitative methods was done on five companies. The paper presents a literature study, the methodology used, the findings and the model that was proposed that showed the process of how CI affects innovative process. Conclusions of the study basing on the findings are presented.
\end{abstract}

Keywords: Competitive Intelligence (CI), Innovation, Product and Services, need pull

\section{INTRODUCTION}

All The ability to innovate is at the heart of every business' survival. When a business runs out of innovative capabilities, then it is bound to exit the fight to attain and keep customers. [1] Contend with this view that "for over 20 years, successful product innovation has been considered a key requirement for business success".

For innovation to realize its full value there is need for the market to buy the final product or service. This necessitates the innovating firm to gather as much knowledge as it can about the needs of the customer, or to create such a need in the market. This kind of creating a need is what [2] called the need pull model. The illustration below shows the model

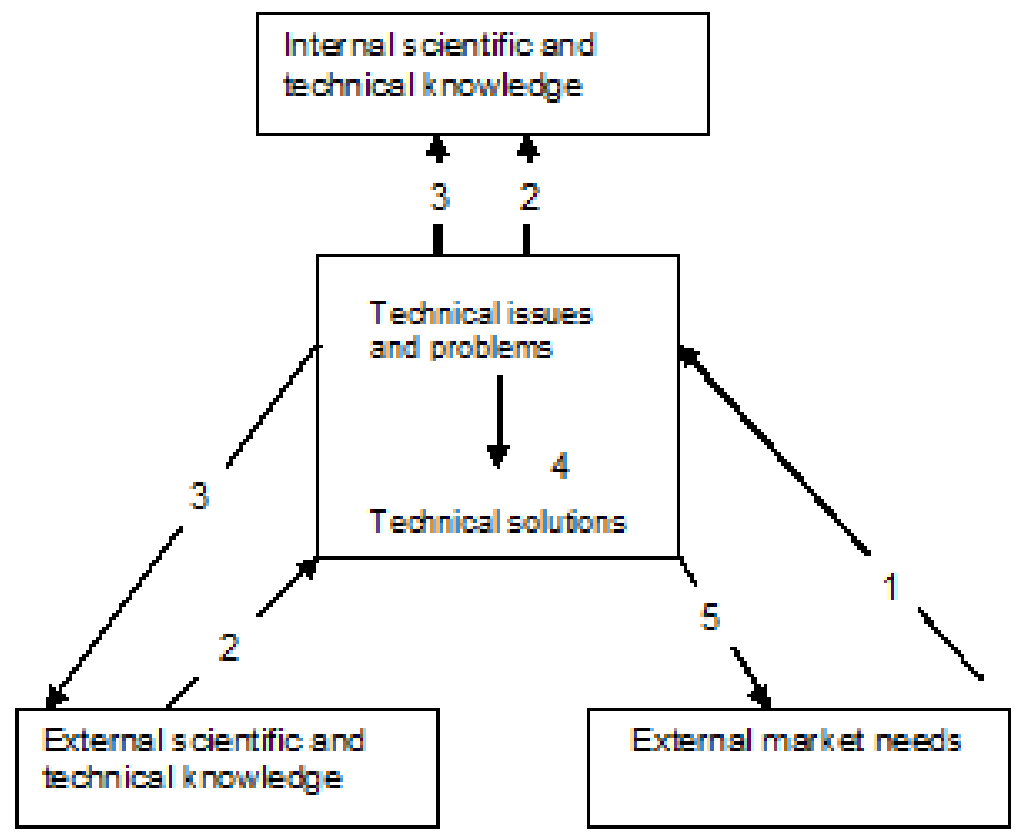

Fig 1: The flow of activities in the "Need pull" model, Adapted from [2]

In the above model the search for a high potential market initiates a search for the inside or outside the firm knowledge to develop an innovative product that would meet market a need. This is the usefulness of Competitive Intelligence to gather the required knowledge to create opportunity in the market.
Yet still despite its apparent role in the innovative process as shown above, [3] had this to say about CI, "Much research widely acknowledges the importance of good CI practice, yet it often goes unnoticed by management." This could explain why $\mathrm{CI}$ is not widely studied as a force that impacts innovation. 
Besides the firm creating a need, there are other needs that are created as a result of responses to the competition. [4] Contends that "Competitive Intelligence units can also help a firm to understand how a rival has developed their own unique capabilities and asset caches, assess a rival's ability to imitate their strategy or assist a company to assess how to uniquely bundle resources to create value for its customers." This way a firm will reposition itself to respond with the situation in the competitive environment. This would be a direct impact of CI.

From the above Need pull model it has been realised that the role of CI in product and service innovation is not ignored per se. but it is also not explicitly stated. The aim of this study has been to bridge the theoretical gap between the practice of CI and innovation. It has shown that CI plays a huge role in product and service innovation.

\section{LITERATURE REVIEW}

The purpose of the study was to establish the role of Competitive Intelligence in product and service innovation. The companies that collect business intelligence should be able to turn the information into a marketable product, service or novel process. The extent to which this is done was at the heart of this study.

According to [5] "The essence of intelligence begins with environmental scanning activities, also known as surveillance. The essence of this process is a transformation of data, information and knowledge into intelligence as a final product." However intelligence as a final product becomes useful if and when the final consumer's needs have been satisfactorily met.

Intelligence is "a process of ethically collecting, analyzing and disseminating precise pertinent, specific, opportunistic, predictable and actionable information about the business environment, competitors and the organization itself [6]." The definition shows the role of information as actionable and pertinent to the organization and business environment. This information becomes actionable when it can help in the strategic and innovative process and therefore adding value for better competition. This is why there is a need to establish how this information is acted upon to create an effect on product and service innovation.

Another value of Competitive Intelligence is the ability to gather consumer opinion. [4] Asserts that "Consumer opinion can offer insight into the benefits of a product or a service as well as consumption tendencies. It can also help identify wishes, dreams and future fantasies." These future fantasies are the heart of the innovative process. As soon as the organisation can gain insight of the wishes of the consumers, this will direct the innovations in an attempt to satisfy the consumer needs. The extent to which the organisations turn this information into a resource for product or service innovation is the reason of this study.

Jeppsen [7] suggest that CI has two basic functions namely to move competitive losses to wins and move competitive pushes (no decisions) to wins. He asserts that "To achieve this kind of impact, Competitive Intelligence must address the core issues of departments that have influence on the drivers of competitive outcomes. According to [8] CI provides value in many ways to the firm that uses it. Specifically, Competitive Intelligence needs to address mission critical issues for sales, marketing, and product development [7]." The issue asserted here is the ability of the users of Competitive Intelligence to transform whatever information they have gathered into an innovative product or service. The best way it will address sales and marketing is providing an innovative product or service in addition to formulating a formidable strategy. Hence the purpose of the study was to establish how far CI contributes to the process of product and service innovation.

\section{METHODOLOGY}

The study was descriptive because it was aimed at answering the question "what". Descriptive study according to [9] "tries to discover answers to the questions who, what, when, where, and sometimes, how. The researcher attempts to describe or define a subject..." The aim was to establish what the effect of Competitive Intelligence on product innovation is.

\subsection{Participating organizations}

The research was carried out in five organizations where Competitive Intelligence is functioning. This is because in organizations where Competitive Intelligence in use, management has already formed an opinion about the impact of its use.

The study was both qualitative and quantitative. According to [9] "qualitative refers to the meaning, the definition or analogy or model or metaphor charactering something, while quantitative assumes the meaning and refers to the measure of it." The research had a qualitative attribute because this allowed the researcher to gather perceptions and opinion about Competitive Intelligence. The quantitative view gathered the proportions of the practitioners of Competitive Intelligence and be able to generalize their opinion. Since the study collected opinion about the effect of Competitive Intelligence in the innovation process, these opinions were recorded as qualitative data because reference would be made about them in the form of quotes. These opinions were gathered through semi-structured interviews of senior managers.

The other part of the data gathered was done quantitatively because there was need for generalizations to be made. Such generalizations would require representative samples from which inferences could be made, [10] this data was gathered by use of an open ended and close ended self-administered questionnaire.

The organizations that were selected purposively were those that make use of Competitive Intelligence and offer a service or product or both that needs innovativeness.

The measures aimed at establishing how Competitive Intelligence impacts product and service innovation.

\subsection{Study population}

The population involved workers in the organizations which have implemented Competitive Intelligence efforts. This is because these are the people who experience the impact of information gathered on the daily basis. Specific interest was on the people who directly use the information to make decisions and those who work directly under them. This is because while those who use the information may have an opinion, their objectivity is easily checked by those who 
have to implement the decisions they make as a result of using the information.

The sample included at least three key decision makers of every organization sampled. This provided a representative sample from each organization to be studied. The selection of the sample was by stratified random sampling. This is a selection method that will help draw proportionate samples representative of each organization and still be able to stratify inside the organization to exclude such workers whose view is not the target of the this initiative like support staff in kitchen and company drivers. ([11], [10]).

\subsection{Sources of information}

There was a pilot study to test the validity and reliability of the questionnaires and find out if they collect the necessary information. A pilot study tests a preliminary research instrument, [9] the aim of this is to detect flaws in the instrument, identify unclear formulations and remove or modify any questions that may cause discomfort to respondents, [10].

Data was gathered by a mixture of open and close-ended self-administered questionnaires. A close-ended questionnaire according to [9] is a questionnaire that presents the participant with a fixed set of choices with specified alternatives provided. The researcher delivered the questionnaires to the various organizations individually. This enabled the researcher to request respondents to answer in time and to create rapport which was expected to boost morale for the questionnaires to be answered quickly.

There were structured interviews after the self-administered questionnaires. These helped to collect information that cannot be collected from the self-administered questionnaires, and which will form the qualitative part of the data collected.

\section{FINDINGS}

Sub- question one: Does Competitive Intelligence contribute to product and service innovation? Throughout the exercise of analysing the data, it was found that Competitive Intelligence contributes to the process of product or service innovation. This was supported by the statistics like $31 \%$ of the respondents agreed that their companies gather competitive intelligence while $23 \%$ disagreed. $46 \%$ did not know. $50 \%$ agreed that their company makes use of the collected CI while the other $50 \%$ said that their companies did not make use of the collected CI. $62 \%$ of the respondents agreed that $\mathrm{CI}$ has a role in product and service innovation. $54 \%$ of respondents accepted participation in their companies' innovative processes. It was concluded that CI had a role to play in product and service innovation.

Sub- question two: How does Competitive Intelligence contribute to product or service innovation? This question was based on question one being answered in the affirmative. 54\% of the respondents found Competitive Intelligence a useful contributor to the process of service or product innovation. The respondents who found CI a useful contributor to the process of product or service innovation had reasons like; CI points to the customers' needs, shows innovative direction, influences innovative decisions and shows market trends. $54 \%$ of the respondents thought CI helps to meet customer needs. $38 \%$ said that the customer had a say in the innovative process.

From the responses, it was concluded that Competitive Intelligence contributed to product or service innovation.

The qualitative data presented similar responses. For example the respondents mentioned various reasons for in support of Competitive intelligence. These included strategy making, understand the competition, and anticipate market changes. Other responses supported the role of Competitive Intelligence in meeting customers' needs and keeping track of competition. As competition increases and customers become more discriminating, firms are increasingly turning to competitive intelligence to provide insight into competitors' strategies and customers' needs [12]. From the same respondents it appeared unquestionable that Competitive Intelligence played a role in the analysis of the competitive environment. The role allotted to Competitive Intelligence in the process of product or service innovation ranged from thinking out of the box to identifying what no longer works for customers.

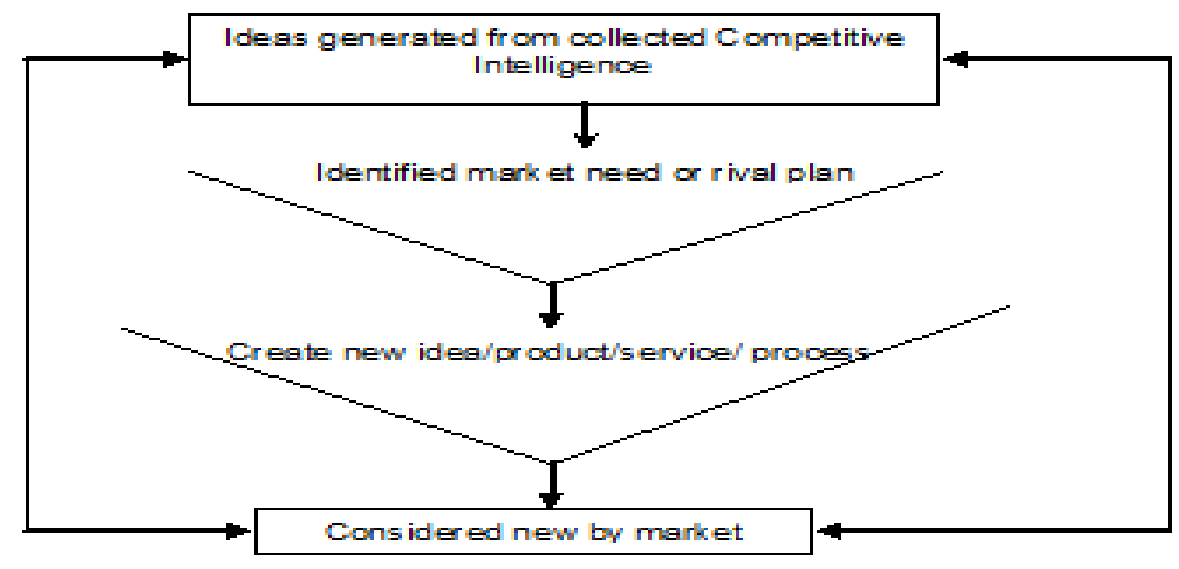

Fig 1: Model of the process of CI's effect on innovation 
The interview responses as noted were in support of what was reported in the questionnaire results. From these responses, a model was proposed to indicate the place of CI on the innovative process.

The model shows that a study of the market creates new ideas for the firm. This enables them to realize new market needs and or rival plans. In response to this they create something new, like a product, a service or even a process. The end result is that the market perceives this as a new innovation upon implementation.

\section{RECOMMENDATIONS}

This research was far from being comprehensive, but it was aimed at connecting the Competitive Intelligence and innovation.

The following are recommendations for further research;

- A study of the relationship that exists between market leadership and Competitive Intelligence.

- A study of the direct impact of Competitive Intelligence and strategic management.

\section{CONCLUSIONS}

It was established that the role of Competitive Intelligence on product and service innovation was to inform strategic management, reflect customer needs, and inform rivals about the competitors and help firms locate themselves on the competitive scale.

It was established Competitive Intelligence is overemphasized as revolutionary yet customers still remain unsatisfied by the services and products because most of Competitive Intelligence remains in talk, but not in execution. This was reflected by the numbers of respondents who said that Competitive Intelligence was not useful because what was collected was not used.

\section{REFERENCES}

[1] Chapman r. L., O’Mara C. E., Ronchi s., A., Corso M., 2001. Continuous product innovation: a comparison of key elements across different contingency sets. Measuring Business Excellence. Pp 16-23. Available

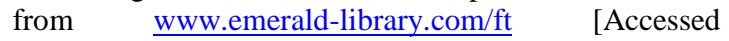
$10 / 08 / 2011]$

[2] Burgelman A.R., Sayles L. R. 2004. Transforming invention into innovation: the conceptualization stage in Burgelman A. R., Christensen C. M., Wheelwright S. C. 2004. Strategic management of technology and innovation 4Ed. McGraw Hill-Irwin Boston.

[3] Badr A., Wright. S., 2004 CI and market strategy formulation Volume 7 • Number 3 - May-June 2004 available at www.scip.org [Accessed 20/08/2011]
[4] Hughes S. Competitive Intelligence as Competitive Advantage: The Theoretical Link between Competitive Intelligence, Strategy and Firm Performance. Journal of Competitive Intelligence and Management $\bullet$ Volume 3 • Number 3 - Available at www.scip.org [Accessed20/08/2011]

[5] Cavalcanti P. E 2005. The Relationship between Business Intelligence and Business Success Journal of Competitive Intelligence and Management $\bullet$ Volume 3 • Number 1 available at www.scip.org [Accessed 20/08/2012]

[6] SCIP. Society of Competitive Intelligence Professionals, Developed by SCIP, Presents various information about professional development of Competitive Intelligence 2003. (www.scip.org).

[7] Jeppsen R. B. (2005). An introduction to impact-based Competitive Intelligence www.scip.org [Accessed 16/ 05/12]

[8] McGonagle, J. John, and M. Carolyn Vella, 2012. "What is Competitive Intelligence and Why Should You Care about it?." Proactive Intelligence: 9-19.

[9] Cooper D R, Schindler P S, 2003. Business research methods $8^{\text {th }}$ ed. McGraw Hill, Boston.

[10] Welman J. C., Kruger S.J, 2001. Research Methodology: for the Business and Administrative sciences, $2^{\text {nd }}$ Ed. Oxford University Press, South Africa, Cape Town

[11] Babbie E. 2005. The Basics of Social Research $9^{\text {th }}$ Ed. Belmont, Wadsworth.

[12]Le Bon J., Rapp A., \& Hughes D. E, 2012. "Competing with competitive intelligence: when salespeople's customer-based information impacts firm performance." Marketing Theory and Applications : 97.

\section{Author' biography}

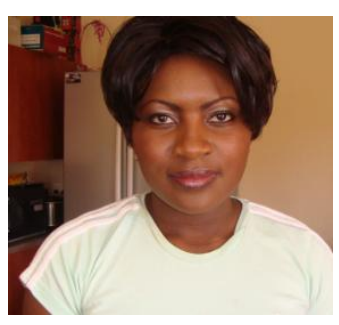

Phathutshedzo Nemutanzhela has a Master's degree (MTech) Business Information Systems from Tshwane University of Technology. She has a Baccalaureus Technologies (BTech): Information Technology (Informatics). Her principle research interest is Competitive Intelligence, Information Systems and innovation. Theoretically, she focuses on Diffusion of Innovation (DoI) Theory. 